ARTICLE

\title{
A connexin30 mutation rescues hearing and reveals roles for gap junctions in cochlear amplification and micromechanics
}

Victoria A. Lukashkina ${ }^{1}$, Snezana Levic ${ }^{1,2}$, Andrei N. Lukashkin ${ }^{1}$, Nicola Strenzke $^{3} \&$ lan J. Russell ${ }^{1}$

Accelerated age-related hearing loss disrupts high-frequency hearing in inbred CD-1 mice. The p.Ala88Val (A88V) mutation in the gene coding for the gap-junction protein connexin30 (Cx30) protects the cochlear basal turn of adult $C D-1 C \times 30^{A 88 V / A 88 V}$ mice from degeneration and rescues hearing. Here we report that the passive compliance of the cochlear partition and active frequency tuning of the basilar membrane are enhanced in the cochleae of $\mathrm{CD}-1 \mathrm{C} \times 30^{\mathrm{A} 88 \mathrm{~V} / \mathrm{A} 88 \mathrm{~V}}$ compared to CBA/J mice with sensitive high-frequency hearing, suggesting that gap junctions contribute to passive cochlear mechanics and energy distribution in the active cochlea. Surprisingly, the endocochlear potential that drives mechanoelectrical transduction currents in outer hair cells and hence cochlear amplification is greatly reduced in $\mathrm{CD}-1 \mathrm{C} \times 30^{\mathrm{A} 88 \mathrm{~V} / \mathrm{A} 88 \mathrm{~V}}$ mice. Yet, the saturating amplitudes of cochlear microphonic potentials in

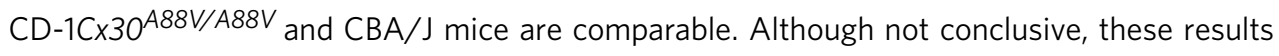
are compatible with the proposal that transmembrane potentials, determined mainly by extracellular potentials, drive somatic electromotility of outer hair cells.

\footnotetext{
${ }^{1}$ Sensory Neuroscience Research Group, School of Pharmacy and Biomolecular Sciences, University of Brighton, Brighton BN2 4GJ, UK. ${ }^{2}$ Brighton and Sussex Medical School, University of Sussex, Brighton BN1 9PX, UK. ${ }^{3}$ Department of Otorhinolaryngology, University Medicine Göttingen, Robert-KochStrasse 40, Göttingen 37075, Germany. Correspondence and requests for materials should be addressed to N.S. (email: NStrenzke@med.uni-goettingen.de) or to I.J.R. (email: I.Russell@brighton.ac.uk).
} 
$\mathrm{R}$ esponses recorded from the cochleae of wild-type (WT) mice are very sensitive and sharply tuned with a frequency range that extends from $\sim 2 \mathrm{kHz}$ to above $100 \mathrm{kHz}$ (ref. 1). These characteristics depend on the inherent mechanical properties of the basilar membrane (BM), which is graded in increasing stiffness from the apex to the base of the cochlea ${ }^{2}$. Signal processing in the cochlea is initiated when sound-induced changes in fluid pressure displace the BM in the transverse direction, causing radial shearing displacements between the surface of the organ of Corti (OC; the reticular lamina) and the overlying tectorial membrane (TM; Fig. 1a) ${ }^{3}$. The stereocilia on the apical surface of outer hair cells (OHCs) provide an elastic link between the OC and the overlying $\mathrm{TM}^{4}$. Deflection of the stereocilia by the radial shear ${ }^{5}$ gates the hair cell's mechanoelectrical transducer (MET) channels, thereby initiating a MET current $^{6}$ that promotes active mechanical force production by the OHCs, which, in turn, influences mechanical interactions between the TM and the $\mathrm{BM}^{7,8}$. This nonlinear frequencydependent enhancement process, which boosts the sensitivity of cochlear responses to low-level sounds and compresses them at high levels, is known as the cochlear amplifier ${ }^{9}$.

These characteristics are shared by all normal-hearing mouse strains, but can be lost with age, initially from the basal, highfrequency regions of the cochlea. High-frequency hearing in the CD-1 mouse deteriorates progressively from about 3 weeks in age ${ }^{10}$. Pathological changes in cochlear fibrocytes, especially in the spiral ligament, precede other presbycusic changes associated with age-related hearing loss (ARHL) in the CD-1 mouse ${ }^{10}$. These fibrocytes, like many cell types in the cochlea, are coupled together by intercellular gap junctions. Each gap junction is formed by two interacting hemichannels (connexons) on neighbouring cells, each consisting of six connexin protein subunits, to permit the bidirectional flow of ions and signalling molecules. The hemichannels of type 1 fibrocytes of the spiral ligament, supporting cells of the sensory epithelium of the cochlea, the OC and cells within the basal cell region of the stria vascularis (SV) are formed of co-localized Cx26 and Cx30 (ref. 11), deletions or mutations of which are responsible for the majority of genetically based hearing $\operatorname{loss}^{12}$. Mutations of Cx30, including A88V (ref. 13), are the basis for Clouston syndrome (OMIM \#129500), an autosomal dominant genetic disorder characterized by alopecia, nail dystrophies, palmoplantar hyperkeratosis and sometimes hearing loss. The CD-1Cx30 $488 V / A 88 V$ mouse model carrying the p.Ala88Val (A88V in NP_001010937.1) point mutation of Cx30 was generated by Bosen et al. $^{13}$ primarily to analyse the skin phenotype that expresses many of the phenotypes of Clouston syndrome. Surprisingly, in addition to mild low-frequency hearing loss, the $\mathrm{A} 88 \mathrm{~V}$ mutation led to rescue of the high-frequency hearing loss expressed in the CD-1 background strain ${ }^{13}$. Here we confirmed this finding and also discovered that active frequency tuning of the BM and apparent passive compliance of cochlear partition are enhanced in the cochleae of CD-1C $\times 30^{A 88 V / A 88 V}$ mice compared to $\mathrm{CBA} / \mathrm{J}$ mice with sensitive high-frequency hearing. CD-1C $x 30^{A 88 V / A 88 V}$ mice preserve excellent sensitivity in their basal cochleae and normal saturating amplitudes of the cochlear microphonic (CM) in spite of the fact that they have a greatly reduced endocochlear potential (EP). We suggest that somatic electromotility depends on $\mathrm{OHC}$ transmembrane potential difference due primarily to extracellular potential changes in the vicinity of the OHCs rather than on $\mathrm{OHC}$ intracellular potentials as originally proposed by Dallos and Evans ${ }^{14}$

\section{Results}

Cx30 similarly located in CD-1Cx30 ${ }^{A 88 V / A 88 V}$ and CBA/J mice. According to the histology and Cx30 immunohistochemistry, the
OC is structurally intact in all turns of the cochleae of $\mathrm{CBA} / \mathrm{J}(n=4)$ and CD-1Cx30 $888 \mathrm{~V} / \mathrm{A} 88 \mathrm{~V}(n=7)$. In contrast, the basal, high-frequency turn of CD-1C $\times 30^{W T / W T}(n=7)$ mice is degenerated, with total loss of OHCs (Fig. 1c). In intact turns of the cochlea (CBA/J and CD-1Cx30A88V/A88V $), C \times 30$ is localized in the membranes of Deiters' cells (DC) and outer pillar cells (OPCs) in the OC and in basal cells of the SV and spiral ligament (Fig. 1).

\section{$\mathrm{CD}-1 \mathrm{C} x 30^{A 88 V / A 88 V}$ mice generate high-frequency DPOAEs.} Distortion product otoacoustic emissions (DPOAEs) are nonlinear acoustical responses of the cochlea recorded in the ear canal in response to simultaneous stimulation with two pure tones $\mathrm{f} 1$ and $\mathrm{f} 2$. DPOAEs are usually dominated by the cubic distortion product at frequency 2f1-f2. DPOAEs are consequences of the nonlinear properties of cochlear mechanosensory transduction mechanisms ${ }^{15}$ and cochlear amplification $^{16}$. Therefore, DPOAE threshold as a function of f2 stimulus frequency provides information about the sensitivity and frequency range of cochlear responses at the level of the OHCs, which is the focus of interest in this study.

Bosen et al. ${ }^{13}$ demonstrated that for frequencies $<10 \mathrm{kHz}$ the thresholds for auditory brainstem responses (ABRs) recorded from $\mathrm{CD}-1 \mathrm{C} \times 30^{A 88 V / A 88 V}$ mice are increased compared to those from their CD-1CX30 ${ }^{W T / W T}$ littermates. However, the thresholds of both ABRs and DPOAEs of CD-1C $\times 30^{A 88 V / A 88 V}$ mice are decreased and their amplitudes increased significantly compared to those of CD-1C $\times 30^{W T / W T}$ littermates for frequencies above $16 \mathrm{kHz}$. Within the sensitivity range of the high-frequency sound system used in our measurements, DPOAE threshold audiograms (Fig. 2a) recorded from CD-1C $x 30^{A 88 V / A 88 V}, \mathrm{CD}-1 C x 30^{W T / W T}$, CBA/J mice are similar for frequencies below $20 \mathrm{kHz}$. Above $20 \mathrm{kHz}$, the audiograms of the CD-1C $\times 30^{W T / W T}$ become less sensitive with increasing frequency. These characteristics may also be observed in the DPOAE magnitudes as functions of $\mathrm{f} 2$ frequency recorded from individual CD-1C $\times 30^{A 88 V / A 88 V}$ (Fig. 2b) and CD-1C $\times 30^{W T / W T}$ (Fig. 2c) mice. The DPOAE audiograms of CD-1Cx30 $A 88 V / A 88 \mathrm{~V}$ and $\mathrm{CBA} / \mathrm{J}$ mice are closely similar and reveal that $\mathrm{OHC}$-mediated mechanical sensitivities of the OCs of CD-1Cx30 $388 \mathrm{~V} / A 88 \mathrm{~V}$ and $\mathrm{CBA} / \mathrm{J}$ mice extend at least to the $70 \mathrm{kHz}$ frequency range. Thus, the DPOAE measurements reported here accord with those reported previously $^{13}$ and further reveal that cochlear sensitivity is preserved across the entire basal turn of the CD-1Cx30 A88V/A88V mouse cochlea.

Reduced EP in CD-1Cx30 $488 V / A 88 V$ and $\mathrm{Cx} 30^{\mathrm{A88V} / \mathrm{WT}}$ mice. The EP is generated by electrogenic secretion of potassium-rich endolymph from the $\mathrm{SV}^{17}$. EP augments the mechanoelectrical transduction (MET) current, hence cochlear amplification. The latter is due to forces produced by prestin-based, voltagedependent, somatic motility of $\mathrm{OHCs}^{18-25}$ and perhaps hair bundle motility ${ }^{26}$, which amplify sound-induced BM vibrations ${ }^{24}$. Reduction of the EP impairs the sensitivity and frequency tuning of cochlear responses ${ }^{27-29}$.

EP was measured in the scala media by advancing the micropipettes through the OC. The EP, expressed as mean \pm s.d. measured from CD $-1 C \times 30^{W T / W T}$ mice was $+112.8 \pm 1.2 \mathrm{mV}$, $n=9$, not significantly different from that measured from CBA/J mice of a similar age $(+114.7 \pm 2.9 \mathrm{mV}, n=4 ; p=0.11$, unpaired two-tailed $t$-test). In contrast, EP was greatly reduced to $+88.4 \pm 2.0 \mathrm{mV}$ in CD-1Cx30 $0^{A 88 V / W T}$ mice $(n=8)$ and to only $+71.3 \pm 2.8 \mathrm{mV} \quad(n=12)$ in $\mathrm{CD}-1 \mathrm{C} \times 30^{A 88 V / A 88 V}$ littermates $\left(p<0.0001\right.$ for CD-1Cx30WT/WT compared to CD-1Cx30 $0^{A 88 V / W T}$ or CD-1C $x 30^{A 88 V / A 88 V}$ mice; $p=0.0016$ for CD-1Cx30 $0^{A 88 V / W T}$ versus $C D-1 C \times 30^{A 88 V / A 88 V}$, unpaired $t$-test). Hence, a higher 
a
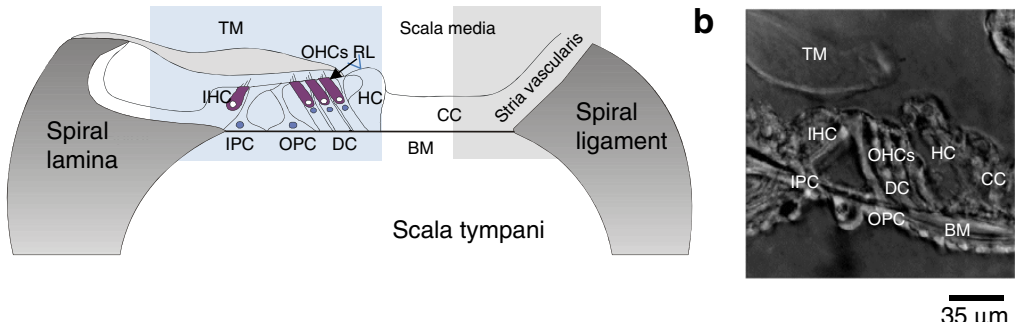

C

CD-1Cx30 WT/WT
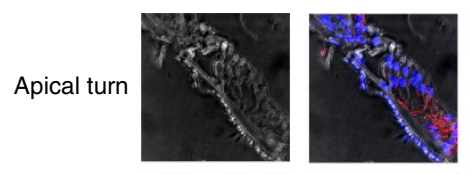

Mid turn
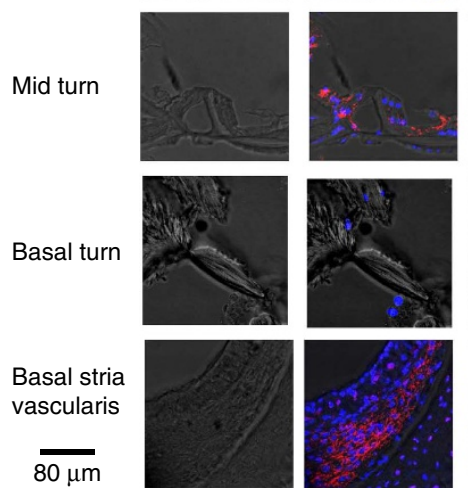

$\mathrm{CD}-1 \mathrm{C} \times 30^{88 \mathrm{~V} / \mathrm{AA} B 8 \mathrm{~V}}$
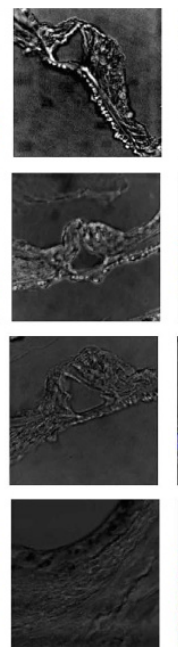
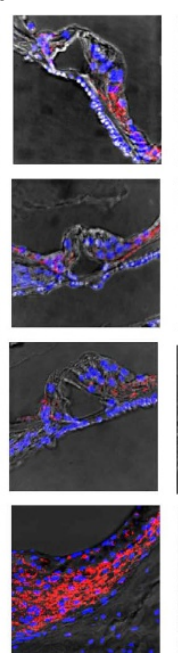

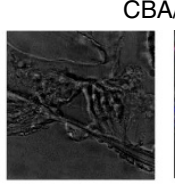

$B A / J$

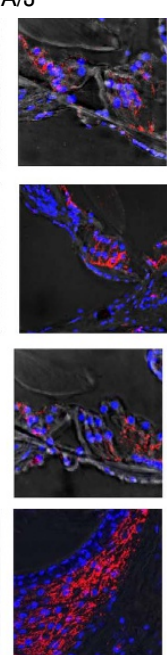

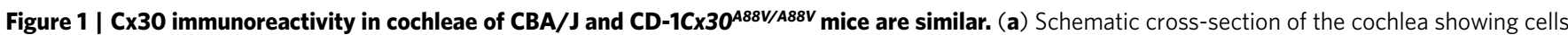
of the sensory epithelium (organ of Corti) including inner pillar cells (IPCs), outer pillar cells (OPCs), Deiters' cells (DCs), Hensen cell (HC), outer hair cell $(\mathrm{OHC})$, inner hair cell (IHC), Claudius cells (CCs) and major non-cellular elements (basilar membrane (BM), tectorial membrane (TM) and reticular laminar (RL); modified with permission from Fig. 1 (ref. 49). (b) Confocal micrograph of $10 \mu \mathrm{m}$ cryosection taken from middle turn of cochlea in $\mathbf{c}$ to identify details of cells and noncellular structures in the organ of Corti. Modified from c. Rows of confocal micrographs of $10 \mu \mathrm{m}$ cryosections of the apical, middle and basal turns of the organ of Corti and stria vascularis. The rows are organized in columns of pairs of micrographs at each location from $C D-1 C \times 30^{\text {WT/WT }}, C D-1 C \times 30^{A 88 V / A 88 V}$ and CBA/J mice. The left of each pair of micrographs shows the unstained section. In the right of each pair, the Cx30 (red) expression is revealed with a selective antibody and nuclei are counterstained with DAPI (blue). OHCs, DCs and spiral lamina cells are intact in all cochlea turns of $\mathrm{CBA} / \mathrm{J}$ and $\mathrm{CD}-1 \mathrm{C} \times 30^{\mathrm{A} 88 \mathrm{~V} / \mathrm{A} 88 \mathrm{~V}}$ mice but not in the basal turn of CD-1Cx30WT/WT mice. $\mathrm{C} \times 30$ appears to be localized in the membranes in basal cells of the stria vascularis, DCs, IPCs, OPCs and spiral lamina cells of the intact OC, that is, in all turns of the cochleae of CBA/J and $\mathrm{CD}-1 \mathrm{C} \times 30^{\mathrm{A} 88 \mathrm{~V} / \mathrm{A} 88 \mathrm{~V}}$ mice. Scale Bar, $35 \mu \mathrm{m}$ (b) and $80 \mu \mathrm{m}$ for all micrographs in $\mathbf{c}$, see blue and grey squares in a for location of histology shown in rows 1-3 (organ of Corti) and 4 (stria vascularis), respectively. All mice were 3 months old.

expression of mutated $\mathrm{Cx} 30 \mathrm{~A} 88 \mathrm{~V}$ protein subunits appears to entail a greater reduction in EP.

CD-1C $x 30^{A 88 V / A 88 V}$ mice produce CM. Cochlear amplification is initiated by the flow of MET current through channels located at the tips of the stereocilia that comprise the OHC hair bundles ${ }^{30}$. The driving force for this $\mathrm{K}^{+}$-dominated current is provided by batteries in series: the resting membrane potential (approximately $-50 \mathrm{mV}$ for $\mathrm{OHCs}^{31,32}$ ) and the EP (approximately $+120 \mathrm{mV}$ in mice $)^{3,33,34}$. The total OHC MET current flow across the total electrical impedance of cochlear partition can be monitored by measuring the CM potential. These extracellular potentials, which can be recorded at the round window (RW), are dominated by basal turn OHC MET currents ${ }^{35,36}$. In this study, we did not use $\mathrm{CM}$ to assess cochlear amplification, sensitivity or frequency selectivity, but to assess mechanoelectrical transduction of OHCs in the basal turn. We therefore stimulated the ear with $5 \mathrm{kHz}$ tones, which is far below the $50-80 \mathrm{kHz}$ frequency range of the basal turn cochlear responses. We chose this frequency because the entire basal turn of the cochlea should be displaced in unison ${ }^{22}$ and at saturating levels of the CM, all OHCs in the basal turn of the cochlea will contribute MET current to the $\mathrm{CM}^{34,35}$. Stimulation with high-frequency tones close to the sensitive frequency range of the basal turn will cause adjacent regions of the cochlear partition of the basal turn to move in opposite directions ${ }^{22}$, thereby causing complex phase augmentation and cancellation of the $\mathrm{CM}^{35}$, which defeats the purpose of the measurement, which is simply to compare the functionality of mechanoelectrical transduction in basal turn OHCs from CD-1C $\times 30^{A 88 V / A 88 V}, \mathrm{CD}-1 C \times 30^{W T / W T}$ and $\mathrm{CD}-1 \mathrm{C} \times 30^{A 88 V / W T}$ littermates with that recorded from control $\mathrm{CBA} / \mathrm{J}$ mice. Any damage to or loss of OHCs will be indicated as a reduction in CM (see Methods), or indeed lack of detectable CM in the case of total absence of functional OHCs in the basal turn of the cochlea. Consistent with our histological findings, we recorded $\mathrm{CM}$ potentials from the OC (Fig. $3 \mathrm{~d}$ ) and RW (Fig. 3d, inset), only from CD-1C $330^{A 88 V / A 88 V}$ mice. CM was not detectable in CD-1Cx30 $30 / W T$ and CD-1C $x 30^{A 88 V / W T}$ littermates (not shown).

We confirmed our RW recordings from CD- 1 C $x 30^{A 88 V / A 88 V}$ mice with sharp quartz glass micropipettes advanced through the RW and BM of the basal turn of the cochlea and into the OC towards the scala media (Fig. 3a). With this approach, we recorded receptor potentials from putative supporting cells with very negative resting potentials $(-108 \pm 0.9 \mathrm{mV}, n=24$; mean \pm s.d., number of cells, Fig. $3 b$ ). Larger receptor potentials 
a

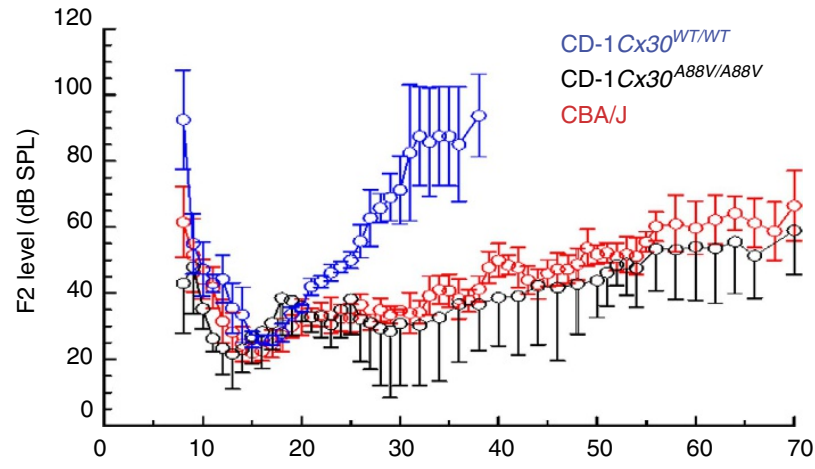

b

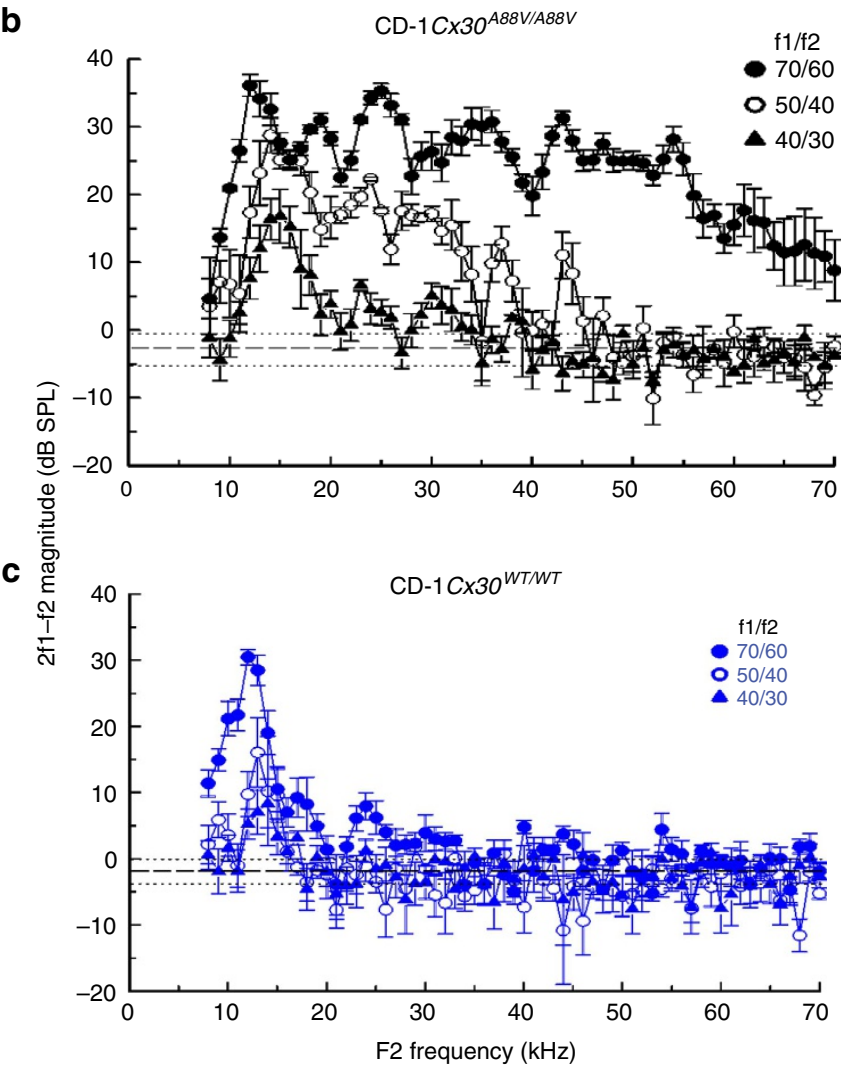

Figure 2 | DPOAE audiograms. (a) DPOAE threshold (2f1-f2, $0 \mathrm{~dB}$ $\mathrm{SPL}$ threshold criterion, mean \pm s.d.) as a function of the $\mathrm{f} 2$ frequency $(\mathrm{f} 2 / \mathrm{f} 1$ ratio $=1.23$; level of $\mathrm{f} 2$ set $10 \mathrm{~dB}$ below $\mathrm{f} 1$ level) from six $\mathrm{CD}-1 \mathrm{C} \times 30^{\mathrm{WT} / W T}$ (blue symbols) and five CD-1C $\times 30^{\mathrm{A} 88 \mathrm{~V} / \mathrm{A} 88 \mathrm{~V}}$

(black symbols) mice, and from seven CBA/J mice (red symbols). The maximum SPL of the sound system was restricted to $\leq 110 \mathrm{~dB}$ for frequencies $\geq 35 \mathrm{kHz}$. (b,c) DPOAE magnitude (2f1-f2, mean \pm s.d.) as a function of the $\mathrm{f} 2$ frequency for five $\mathrm{CD}-1 \mathrm{C} \times 30^{\mathrm{A} 88 \mathrm{~V} / \mathrm{A} 88 \mathrm{~V}}$ mice (b) and five CD-1C $\times 30^{W T / W T}$ mice (c). Stimulus levels and colour and symbol coding for $\mathrm{f} 1$ and $\mathrm{f} 2$ are shown in the figures. $X$ axis: $\mathrm{f} 2$ frequency $(\mathrm{kHz})$ for all figures. Dashed and dotted lines indicate the recording noise floor \pm s.d. for all measurements.

in response to $5 \mathrm{kHz}$ tones were recorded from cells with smaller resting potentials $(-50.6 \pm 2.0 \mathrm{mV}, n=8$, Fig. 3c) that were encountered just before penetrating into the scala media. These cells were tentatively identified as OHCs in that they share the characteristics described previously for OHCs in the basal turn of the guinea pig cochlea ${ }^{37}$. In contrast to intracellular measurements from cells in the guinea pig $\mathrm{OC}^{38}$, we observed a transient hyperpolarizing dip occurring $\sim 2 \mathrm{~ms}$ after tone onset in stable ( $>5 \mathrm{~min}$ duration) intracellular voltage responses recorded from presumed supporting cells and OHCs in the basal turn of the mouse cochlea (arrows in insets of Fig. 3b,c). As its latency is compatible with a combination of travelling wave and synaptic delays it is likely that the transient hyperpolarization represents the compound action potential of the 8th nerve. The potential is also present in extracellular spaces of the OC (Fig. 3d). It would appear that the intracellular recordings from presumed mouse OHCs are electrically more leaky than those made from the guinea pig cochlea, where intracellular recordings of neural potentials have not been seen ${ }^{36,37}$. It is possible, through differential subtraction across the hair cell membranes, that this potential does not influence the electrical responses of the cells within the $\mathrm{OC}$ as has been suggested for other extracellular potentials in measurements from the guinea pig cochlea ${ }^{38}$. Significantly, the peak-to-peak magnitude of the $\mathrm{CM}$ recorded from the extracellular spaces close to the OHCs (Fig. 3d) or from the RW (inset of Fig. 3d) of normal-hearing $\mathrm{CBA} / \mathrm{J}$ mice, and $\mathrm{CD}-1 \mathrm{C} \times 30^{\mathrm{A} 88 \mathrm{~V} / \mathrm{A} 88 \mathrm{~V}}$ mice are very similar for stimulus levels above $75 \mathrm{~dB}$ SPL. For stimulus levels between 40 and $60 \mathrm{~dB}$ SPL, the magnitudes of $\mathrm{CM}$ recorded from the $\mathrm{CBA} / \mathrm{J}$ and $\mathrm{CD}-1 \mathrm{C} \times 30^{A 88 V / A 88 V}$ mice both increase with increasing stimulus level with a slope of 1.12 (close to 1 , Fig. 3d, dotted line). However, the amplitude of CM measured from CD-1C $\times 30^{A 88 V / A 88 V}$ mice for any given stimulus level below $\sim 60 \mathrm{~dB}$ SPL, is only $45 \%$ of that recorded from $\mathrm{CBA} / \mathrm{J}$ mice (Fig. 3d).

Sharp sensitive BM tuning in CD-1Cx30 ${ }^{A 88 V / A 88 V}$ mice. The ability to resolve sound into individual frequency components depends on BM frequency tuning ${ }^{29}$. BM displacement threshold frequency tuning curves $(0.2 \mathrm{~nm}$ criteria) were measured from the cochleae of five CD-1C $x 30^{W T / W T}$ mice, five CD-1C $\times 30^{A 88 V / W T}$ mice, eight CD-1Cx30A88V/A88V mice, five CD-1 as controls for the background of the CD-1Cx30 $0^{A 88 V / A 88 V}$ mice, and four CBA/J mice as examples of mice with excellent hearing and without early onset ARHL. A laser diode self-mixing interferometer was focused through the RW membrane onto locations one third across the width (coincident with outer pillar cells-row 1 OHCs) of the basal turn BM from its attachment to the spiral lamina (Fig. 3a). In this location, which corresponded to the $50-56 \mathrm{kHz}$ region of the $\mathrm{BM}$, magnitude and phase of BM displacement was measured in response to pure tones. BM displacement threshold frequency tuning curves of CD-1Cx30A88V/WT (Fig. 4a) and CD-1Cx30 ${ }^{W T / W T}$ (Fig. 4a,b) mice are similar to those of CD-1 mice (Fig. 4c) with broad, insensitive minima in the $45-55 \mathrm{kHz}$ range. Post mortem, responses are mostly unchanged (Fig. $4 \mathrm{~b}, \mathrm{c})$. Thus, in support of the immunohistochemistry and $\mathrm{CM}$ measurements, it appears there are no functional OHCs in the basal turn of CD-1C $\times 30^{W T / W T}$ and CD-1C $\times 30^{A 88 V / W T}$ littermates and CD-1 strain mice.

Examples of BM displacement threshold frequency tuning curves for $\mathrm{CD}-1 \mathrm{C} \times 30^{A 88 V / A 88 V}$ mice measured from the $50-56 \mathrm{kHz}$ region of the $\mathrm{BM}$ are shown in Fig. 4a,d,e. For comparison, Fig. 4e shows data from a $\mathrm{CBA} / \mathrm{J}$ mouse with a CF that coincides with the $\mathrm{CF}$ of the $\mathrm{CD}-1 \mathrm{C} \times 30^{A 88 V / A 88 V}$ frequency tuning curve. Thresholds and frequency tuning in $\mathrm{CBA} / \mathrm{J}$ mice was very well comparable with published data sets from WT Otoa ${ }^{E G F P / E G F P}$ (ref. 39) and WT Tectb ${ }^{40}$ mice. In contrast, the thresholds of the tuning curves measured from $\mathrm{CD}-1 \mathrm{C} \times 30^{A 88 V / A 88 V}$ mice are $22.7 \pm 5.8 \mathrm{~dB} \operatorname{SPL}(n=8)$. These were not significantly different from the thresholds measured in CBA/J mice $(24.8 \pm 3.7 \mathrm{~dB}$ SPL, $n=4, p=0.78$, 

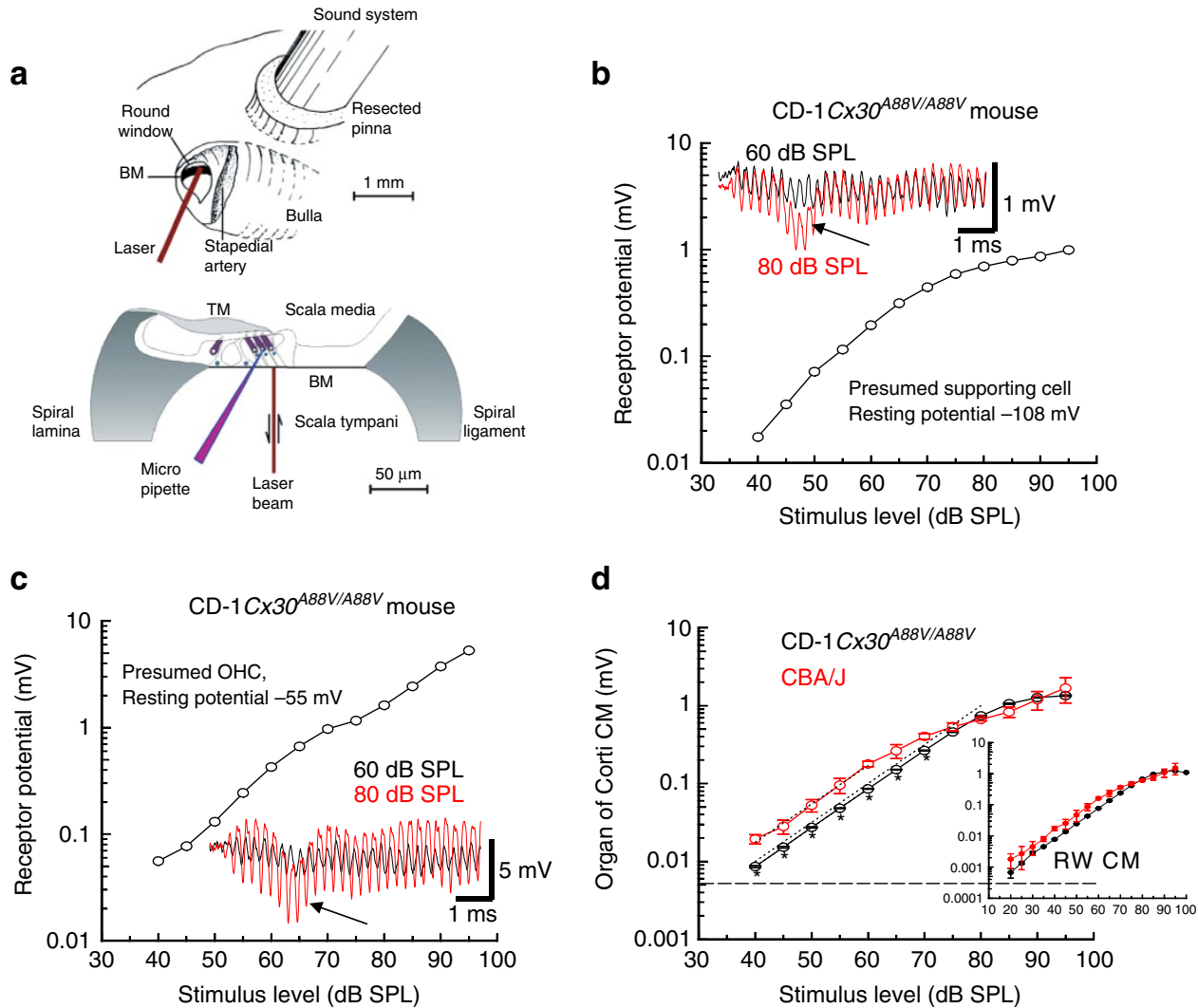

Figure 3 | Magnitude of receptor potential and $\mathbf{C M}$ as functions of stimulus level. Recordings from the basal turn cochleae of $C D-1 C \times 30^{A 88 V / A 88 V}$ and $\mathrm{CBA} / \mathrm{J}$ mice in response to $5 \mathrm{kHz}$ tones. (a) Techniques (in addition to those presented in Fig. 2) used to make acoustic, electrophysiological and mechanical measurements from the cochlea (modified with permission from refs 39,40). (b) Peak-to-peak magnitude of an intracellular receptor potential recorded from a presumed supporting cell from a CD-1C $\times 30^{A 88 V / A 88 V}$ mouse in response to a $5 \mathrm{kHz}$ tone as a function of stimulus level (representative example). (c) Magnitude of an intracellular receptor potential of a presumed OHC of a CD-1C $\times 30^{A 88 V / A 88 V}$ mouse in response to a $5 \mathrm{kHz}$ tone as a function of stimulus level (representative example). Insets in $\mathbf{b}$ and $\mathbf{c}$ show voltage responses to $5 \mathrm{kHz}$ tones made at tone onset; stimulus levels: $60 \mathrm{~dB}$ SPL, black; $80 \mathrm{~dB} \mathrm{SPL}$, red. Arrows, insets of $\mathbf{b}$ and $\mathbf{c}$ indicate negative peak of presumed compound action potential. (d) Compound extracellular receptor potentials (organ of Corti CM), as functions of stimulus level to $5 \mathrm{kHz}$ tones, measured close to the middle row of $\mathrm{OHCs}$ (mean $\pm \mathrm{s}$.d.) from cochleae of CBA/J (red, $n=5$ ) mice and CD-1CX30A88V/A88V (black, $n=4$ ) mice. Asterisks: significantly different (unpaired $t$-test, $\leq 0.05$ two-tailed $p$ value). Dashed line: recording noise floor for $\mathbf{d}$ and inset; $C M$ responses were not seen at any level above this floor for $C D-1 C \times 30^{A 88 V / W T}$ and CD-1C $\times 30^{W T / W T}$ mice. Dotted lines: slope of one. Inset, CM recorded from the round windows of the same group of mice (RW CM).

two-tailed unpaired $t$-test). In contrast, the bandwidths of the tuning curves measured from $\mathrm{CD}-1 \mathrm{C} \times 30^{\mathrm{A} 88 \mathrm{~V} / \mathrm{A} 88 \mathrm{~V}}$ mice were significantly narrower than those of WT mice: the $\mathrm{Q}_{10 \mathrm{~dB}}$ value (characteristic frequency/bandwidth $10 \mathrm{~dB}$ from tip) of $\mathrm{CD}-1 \mathrm{C} \times 30^{A 88 V / A 88 V}$ was $17.4 \pm 3.1$ (mean \pm s.d.) compared with $8.7 \pm 4.3$ for $\mathrm{CBA} / \mathrm{J}$ mice $(p=0.0023$, two-tailed unpaired $t$-test). The high- and low-frequency slopes of BM tuning curves, measured from the tip, to $20 \mathrm{~dB}$ above the tip, from $\mathrm{CD}-1 \mathrm{C} \times 30^{\mathrm{A} 88 \mathrm{~V} / \mathrm{A} 88 \mathrm{~V}}$ mice were $147 \pm 8$ and $322 \pm 15 \mathrm{~dB}$ per octave, respectively, which is significantly steeper than in CBA/J mice of $99 \pm 6$ and $187 \pm 11 \mathrm{~dB}$ per octave $(p<0.0001$ for high- and low-frequency slopes, two-tailed unpaired $t$-test). $\mathrm{Q}_{10 \mathrm{~dB}}$ of CD-1Cx30 $0^{A 88 V / A 88 V}$ mice was correlated $(r=-0.975)$ with the sensitivity at the tip of the threshold tuning curve; the more sensitive the preparation, the sharper the tuning (Fig. $4 \mathrm{~d}$, inset). In line with our interpretation that the sharp amplified tip of the threshold curves for $C \times 30^{A 88 V / A 88 V}$ mice derives from active processes, the sensitivity of post-mortem BM tuning curves of $\mathrm{CD}-1 \mathrm{C} \times 30^{\mathrm{A} 88 \mathrm{~V} / \mathrm{A} 88 \mathrm{~V}}$ mice (Fig. 4d) resembled those of CD-1Cx30 $0^{W T / W T}$ mice (Fig. 4a,b).

The phase of $\mathrm{BM}$ responses as functions of stimulus frequency (relative to that of the malleus) were measured from $\mathrm{CD}-1 \mathrm{C} \times 30^{A 88 V / A 88 V}$ and CBA/J mice (Fig. $4 \mathrm{f}$ ) with a common CF
(Fig. 4e) at stimulus levels where the BM mechanics are dominated by its passive behaviour $(70 \mathrm{~dB}$ SPL). The phasefrequency relationships of the CD-1Cx30 $188 \mathrm{~V} / \mathrm{A} 88 \mathrm{~V}$ and $\mathrm{CBA} / \mathrm{J}$ mice are similar in the low-frequency tail region. However, for frequencies in the range of $45-55 \mathrm{kHz}$, the phase-frequency relations of the $\mathrm{CD}-1 \mathrm{C} \times 30^{A 88 V / A 88 V}$ mouse are steeper than those of the CBA/J mouse (Fig. 4f, inset and caption), which may indicate that gap junctions contribute to energy distribution in the active cochlea resulting in the observed sharper frequency tuning of $\mathrm{CD}-1 \mathrm{C} \times 30^{\mathrm{A} 88 \mathrm{~V} / \mathrm{A} 88 \mathrm{~V}}$ mice.

Enhanced passive BM mechanics in CD-1Cx30 ${ }^{A 88 V / A 88 V}$ mice. It is generally accepted that for the tail frequencies of the BM displacement threshold frequency tuning curves the BM response is dominated by stiffness of cochlear partition at a given cochlear location ${ }^{41}$. Thresholds of the tails between 15 and $40 \mathrm{kHz}$ were significantly more sensitive (Fig. 4e, inset) in $\mathrm{CD}-1 \mathrm{C} \times 30^{A 88 V / A 88 V}$ mice than in CBA/J mice by $11.0 \pm 0.8 \mathrm{~dB}$ SPL $(n=5)$. No significant difference could be observed at $10 \mathrm{kHz}$, which we attribute to the large noise floor, which made measurements difficult. We were unable to detect a significant difference in the phase of BM displacement in 


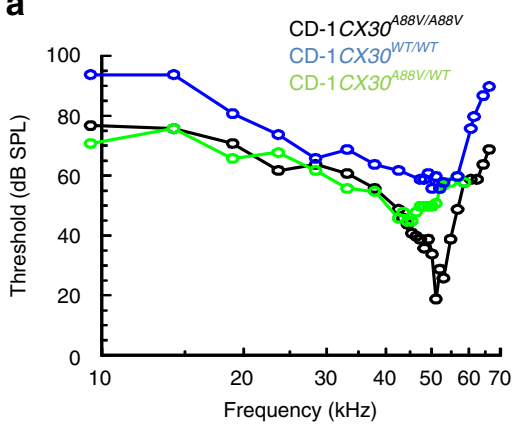

d

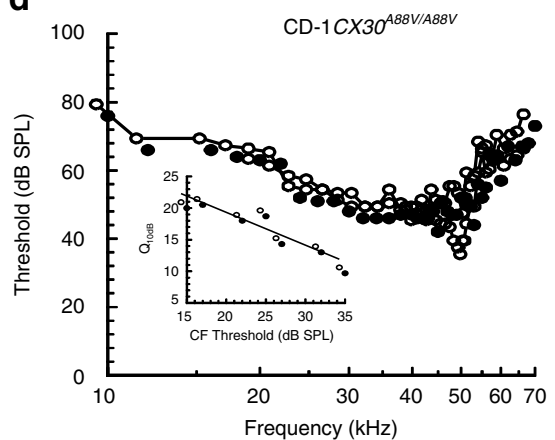

b

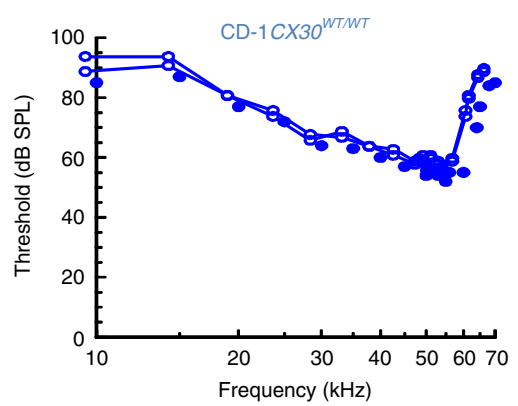

e

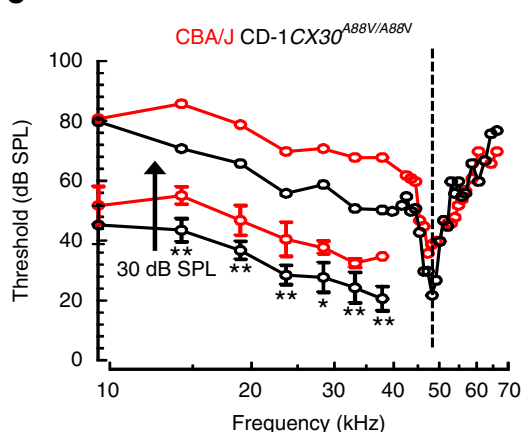

C

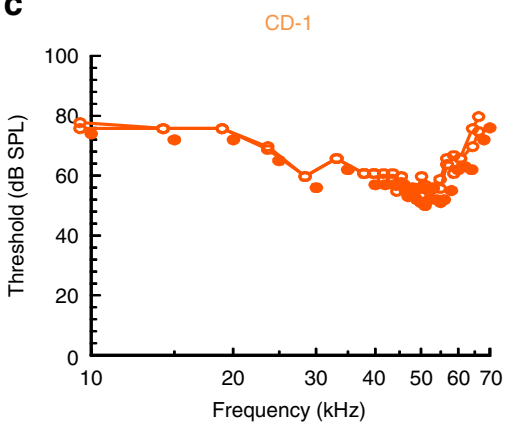

$\mathbf{f}$

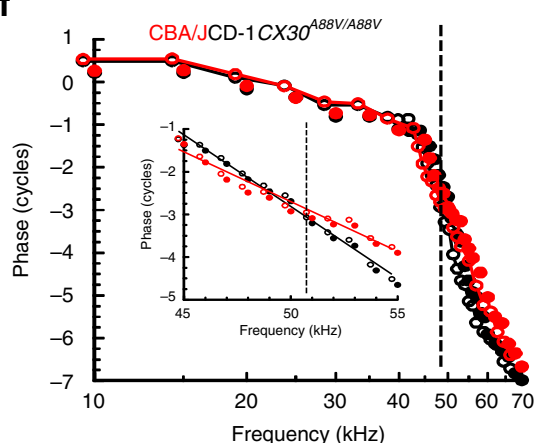

Figure 4 | Basilar membrane displacement frequency tuning curves and phase. (a-e) BM displacement threshold ( $0.2 \mathrm{~nm}$ criterion) as a function of stimulus frequency measured from the basal turn of the cochlea. Strain and genetic state of individual mice identified in the wording and colour of the captions at the top of each figure (CD-1Cx30A88V/A88V (black), CD-1Cx30WT/WT (blue), CD-1Cx30A88V/WT (green), CD-1 (orange) CBA/J (red)). Curves with solid symbols in b-d are post-mortem measurements from the same preparations. Inset to $\mathbf{d}$ : $\mathrm{Q}_{10} \mathrm{~dB}$ as a function of threshold at the tuning curve tip for $C D-1 C \times 30^{A 88 V / A 88 V}$ mice. (e) Inset to e: mean \pm s.d., $n=5$ of the $10-40 \mathrm{kHz}$ region of tuning curves for CBA/J and CD-1Cx30A88V/A88V. For clarity, the curves are displaced downwards by $30 \mathrm{~dB}$ SPL. Asterisks: significantly different (unpaired $t$-test, ${ }^{\star \star} 0.01,{ }^{\star} 0.05$ two-tailed $p$ value). (f) Phase of $\mathrm{BM}$ responses (measured at $70 \mathrm{~dB} \mathrm{SPL}$ ) (open symbols) as a function of frequency for tuning curves shown in e. Solid symbols, mean \pm s.d. of phase $(10-45 \mathrm{kHz})$ from five each of CD-1C $\times 30^{\mathrm{A} 88 \mathrm{~V} / \mathrm{A} 88 \mathrm{~V}}$ and CBA/J mice. Inset to $\mathrm{f}$ : linear plots of expanded section of curves between $45 \mathrm{and} 55 \mathrm{~Hz}$. The slopes of regression reveal that the phase of $B M$ responses from the CBA/J mouse decreases by $-0.232 \pm$ s.e. 0.014 cycles per $\mathrm{kHz}$ and that from the $\mathrm{CD}-1 \mathrm{C} \times 30^{\mathrm{A} 88 \mathrm{~V} / \mathrm{A} 88 \mathrm{~V}}$ mouse decreases by $-0.335 \pm$ s.e. 0.011 cycles per $\mathrm{kHz}$.

the tails of the low-frequency tuning curves in the $10-45 \mathrm{kHz}$ region (expressed as mean \pm s.d., $n=5$, Fig. 4f). The sensitivities of the low-frequency tails of CBA/J, CD-1 and CD-1C $\times 30^{W T / W T}$ mice are similar (not shown but can be deduced from Fig. $4 a-c, e$ ), while the sensitivities of the low-frequency tails of tuning curves from $\mathrm{CD}-1 \mathrm{C} \times 30^{A 88 \mathrm{~V} / W T}$ mice (not shown) are more variable and less sensitive than those of $\mathrm{CD}-1 \mathrm{C} \times 30^{A 88 V / A 88 V}$ mice by $3.2 \pm 1.6 \mathrm{~dB}$ SPL. It is likely that the gap junctions contribute to the passive stiffness of the cochlear partition because increased sensitivity of the low-frequency tail in CD-1Cx30 $0^{A 88 V / A 88 V}$ mice and, hence, decreased mechanical stiffness of the cochlear partition persisted post mortem.

\section{Discussion}

If, as generally accepted, MET current flow is controlled by EP in series with the hair cell resting potential ${ }^{3,34}$, it is remarkable that DPOAE audiograms and BM sensitivity in the basal turn of $\mathrm{CD}-1 \mathrm{C} \times 30^{A 88 V / A 88 V}$ mice are similar to those of CBA/J and other WT mice with excellent hearing ${ }^{42-45}$. Indeed, as a consequence of the reduced EP, the driving force for MET current flow through the $\mathrm{OHC}$ hair bundles in $\mathrm{CD}-1 \mathrm{C} \times 30^{A 88 V / A 88 V}$ mice should be reduced to $73 \%$ of the $\mathrm{CBA} / \mathrm{J}$ mouse values $\left(\mathrm{EP}_{\mathrm{Cx} 30 \mathrm{~A} 88 \mathrm{~V}} 71.3 \mathrm{mV}+-\mathrm{E}_{\mathrm{OHC}}\right) /\left(\mathrm{EP}_{\mathrm{CBA} / \mathrm{J}} 114.7 \mathrm{mV}+-E_{\mathrm{OHC}}\right)$; $E_{\mathrm{OHC}}=-50 \mathrm{mV}$ (refs 3,33,34). Nonetheless, the maximal magnitudes of $\mathrm{CM}$ potentials in $\mathrm{CD}-1 \mathrm{C} \times 30^{A 88 V / A 88 V}$ mice are similar to those of $\mathrm{CBA} / \mathrm{J}$ mice. We have no good reason to assume changes in the number or function of OHCs involved in
CM generation under these stimulus conditions. Thus, the finding of a preserved CM in spite of reduced transduction currents would indicate an increased electrical impedance of the cochlear partition in the mutant mice ${ }^{33}$. Indeed, a reduction in gap-junction conductance in CD-1C $\times 30^{A 88 V / A 88 V}$ has been demonstrated in vitro. Using electrophysiological analysis of paired Xenopus oocytes, Teubner and colleagues ${ }^{46}$ reported that the junctional conductance was smaller in cells expressing A88V Cx30 than in those connected by WT Cx30. The channels made by A88V Cx30 differed from those made by the WT form in their voltage gating properties ${ }^{46}$. It was proposed ${ }^{46}$ that the lower conductance values recorded in homotypic A88V pairs could be due to either or both of two mechanisms: (i) a reduced inter-connexon affinity in homotypic configuration, which results in a poor efficiency in channel formation and/or, (ii) altered intrinsic channel properties such as favouring a closed state in the absence of a transjunctional potential, reducing the open time probability and/or unitary conductance. Our hypothesis remains tentative until it is discovered how exactly the conductance properties of gap junctions expressing mutated Cx30 A88V connexins in the cochlea are changed and how this affects the electrical impedance of the cochlear partition in $\mathrm{CD}-1 \mathrm{C} \times 30^{A 88 V / A 88 V}$ and CD-1Cx30 $0^{A 88 V / W T}$ mice. In addition, the $C \times 30^{A 88 V / A 88 V}$ mice may also become a useful mouse model to study the role for $\mathrm{Cx} 30$ in the generation of the EP. It is known that genetic disruption of the gene coding for $\mathrm{Cx} 30$ leads to disruption of the tight-junctional networks of the SV and elimination of the $\mathrm{EP}^{47,48}$. However, such studies on knockout 
mice are complicated by the genetic interactions between the Cx26 and Cx30 genes ${ }^{49}$, and the possibility of compensation for the complete absence of Cx30 by overexpression of Cx26 (ref. 50).

As EP is reduced, the MET currents in individual $\mathrm{OHC}$ of $\mathrm{CD}-1 \mathrm{C} \times 30^{\mathrm{A} 88 \mathrm{~V} / \mathrm{A} 8 \mathrm{~V} V}$ mutants must be reduced not only at high but also at low stimulus intensities. To explain the preserved cochlear sensitivity, we suggest the predominant factor controlling $\mathrm{OHC}$ electromotility is not a change in the $\mathrm{OHC}$ intracellular potential resulting from the changing current flux through the OHC MET conductance ${ }^{32}$. Instead, our data support the proposal that voltage-dependent amplification is controlled by the $\mathrm{OHC}$ transmembrane potential changes which are due predominantly to changes in the OC potentials extracellular to the OHCs ${ }^{14,51,52}$. In this sense, the extracellular potentials in the vicinity of the OHCs provide 'a floating ground' for the OHC transmembrane potential. These potentials ${ }^{14}$ are generated by the flow of soundinduced MET currents along their return pathways through the electrical impedance of the cochlear partition ${ }^{33,53}$, which we tentatively propose is increased in CD-1C $330^{A 88 V / A 88 V}$ mice. Control of somatic motility by extracellular OC potentials would also enable the bandwidth of cochlear amplification to be limited only by that of the voltage-dependent motility itself $f^{54}$.

Thresholds in the low-frequency tails of the BM tuning curves are reduced in $\mathrm{CD}-1 \mathrm{C} \times 30^{\mathrm{A} 88 \mathrm{~V} / \mathrm{A} 88 \mathrm{~V}}$ mice that may indicate a decrease in the apparent stiffness component of the complex mechanical impedance of the cochlear partition at these frequencies that would need to be confirmed in future direct measurements. The threshold reduction is not associated with observable phase changes. This may not be surprising because a reduction in stiffness of a system is associated not with phase changes but only with amplitude changes in the frequency range where the responses of the system are dominated by stiffness rather than by active nonlinear amplification, as it is the case in the low-frequency tails of the frequency tuning curves $^{22}$. We tentatively propose that a common factor may be responsible for the enhanced $\mathrm{BM}$ frequency tuning of $\mathrm{CD}-1 \mathrm{C} \times 30^{\mathrm{A} 88 \mathrm{~V} / \mathrm{A} 88 \mathrm{~V}}$ mice compared with $\mathrm{CBA} / \mathrm{J}$ and other sensitive wild-type mice ${ }^{39,40}$ and for the reduced $\mathrm{CM}$ magnitude in response to low-intensity low-frequency tones. This proposed factor is a decrease in mechanical coupling within the cochlear partition due to the Cx30 A88V mutation. A similar change in the longitudinal mechanical properties of elements of the cochlear partition has previously been shown to sharpen the mechanical tuning of the cochlea in Tectb ${ }^{-/-}$mice where the number of OHCs contributing towards amplification at a given cochlear location is reduced compared with that in control mice ${ }^{40}$. Here that element is the extracellular matrix of the TM and the change in its mechanical properties was attributed to loss of elastic coupling along its length ${ }^{55}$ due to the loss of the major TM protein $\beta$-tectorin ${ }^{56,57}$.

Indeed, gap junctions, the targets of the $C \times 30 \mathrm{~A} 88 \mathrm{~V}$ mutation, have previously been suggested to influence the mechanical properties of the cochlear partition ${ }^{58,59}$. It has been shown that gap junctions are mechanically sensitive in the inner ear ${ }^{60}$ and that their disruption impairs cochlear amplification ${ }^{61}$. It is proposed that changes in the properties of the mutated gap junctions could directly or indirectly provide a means for a change in longitudinal and perhaps radial coupling in the cochlear partition as a consequence of the $C \times 30 \mathrm{~A} 88 \mathrm{~V}$ mutation.

Similarly, reduced mechanical coupling within the cochlear partition with consequent smaller spread of excitation, can account for $\mathrm{CM}$ differences between $\mathrm{CD}-1 \mathrm{C} \times 30^{A 88 V / A 88 V}$ and $\mathrm{CBA} / \mathrm{J}$ mice at stimulation levels $<60 \mathrm{~dB}$ SPL. It has previously been proposed that the CM, which reflects the total MET current generated in the basal turn in response to low-frequency tones, increases linearly with stimulus intensity as a consequence of (i) increased flow of MET current through each $\mathrm{OHC}$ and (ii) increased spread of excitation along the cochlear partition ${ }^{36}$. From our findings we propose that for stimulus levels $<60 \mathrm{~dB}$ SPL), the spread of excitation and consequent recruitment of $\mathrm{OHCs}$ is more restricted in $\mathrm{CD}-1 \mathrm{C} \times 30^{A 88 \mathrm{~V} / \mathrm{A} 88 \mathrm{~V}}$ mice than in the $\mathrm{CBA} / \mathrm{J}$ mice because of a reduction in mechanical coupling within the basal cochlear partition. Only when the tone level exceeds $\sim 60 \mathrm{~dB}$ SPL would more of the BM be recruited by the $5 \mathrm{kHz}$ tone when the entire basal turn OHCs contribute to generation of the CM recorded at the RW.

Our in vivo data describing the effects of the $A 88 \mathrm{~V}$ mutation of Cx30 provides indirect evidence for new potential roles for gap junctions in sensory processing in the cochlea. Further in vivo and in vitro measurements are required to understand how the mutation influences the electrical and mechanosensitive properties of cochlear gap junction and how this alters the complex electrical environment of OHCs, thereby enabling them to contribute fully in their sensory-motor role to the sensitivity of the cochlea, how gap junctions contribute to the static and dynamic mechanical properties of the cochlear partition, and finally how the mutation rescues hearing in a mouse line that normally expresses accelerated ARHL.

\section{Methods}

Animals. Homozygous $C \times 30^{A 88 V / A 88 V}$ mice from a colony generated and supplied to us by Bosen et al. ${ }^{13}$ formed the basis for a new colony of $C \times 30^{A 88 V}$ mice maintained under quiet conditions in our facility. All experiments were performed with littermates, male and female, of $>96.9 \%$ CD-1 background ( $>5$ back crosses to the CD-1 background). CBA/J mice were obtained from Envigo.com, UK. All mice used in this study were kept under standard housing conditions with a $12 \mathrm{~h} / 12 \mathrm{~h}$ dark-light cycle and with food and water ad libitum. Genotyping was performed according to the protocol provided by Bosen et al. ${ }^{13}$. All procedures involving animals were performed in accordance with the UK Home Office regulations with approval from the University of Brighton Animal Welfare and Ethical Review Body.

Histological and immunofluorescence analyses. Isolated inner ear tissue was fixed with $4 \%$ paraformaldehyde in phosphate-buffered saline (PBS) for $2 \mathrm{~h}$, then rinsed and frozen in Tissue-Tek embedding medium (Sakura, Zoeterwonde, The Netherlands), cryosectioned $(\sim 10 \mu \mathrm{m})$, and immunostained with antibodies following standard protocols. The antibodies used were directed against rabbit anti-Cx30 (polyclonal, 1:250, Invitrogen, catalogue no. 71-2200). Immunostaining was visualized using Alexa Fluor 594 goat anti-rabbit $\operatorname{IgG}(1: 1,000$, Invitrogen, catalogue no. A-11037, CA, USA).

Omission of the primary antibodies eliminated staining in all preparations examined. The nucleus was counterstained with DAPI. A Leica confocal microscope was used to collect images. Leica LAS AF and Image-J software were used to collect and generate images.

Physiological recordings. Mice, 3-5 weeks of age, were anaesthetized with ketamine $\left(0.12 \mathrm{mgg}^{-1}\right.$ body weight i.p.) and xylazine $\left(0.01 \mathrm{mgg}^{-1}\right.$ body weight i.p.) for nonsurgical procedures or with urethane (ethyl carbamate; $2 \mathrm{mg} \mathrm{g}^{-1}$ body weight i.p.) for surgical procedures. The animals were tracheotomized, and their core temperature was maintained at $38^{\circ} \mathrm{C}$. To measure $\mathrm{BM}$ displacements, $\mathrm{CM}$ (Fig. 2a), a caudal opening was made in the ventro-lateral aspect of the right bulla to reveal the RW. CM potentials were measured from the RW membrane by using glass pipettes filled with artificial perilymph, with tip diameters of $50-100 \mu \mathrm{m}$ (recording bandwidth $>30 \mathrm{kHz}$ ). Signals were amplified with a recording bandwidth of d.c. to $100 \mathrm{kHz}$ using a laboratory designed and constructed preamplifier. With low-impedance electrodes, CM was measured at levels of $20 \mathrm{~dB}$ SPL in response to $5 \mathrm{kHz}$ tones in mice with DPOAE responses that were sensitive throughout the $1-70 \mathrm{kHz}$ range of the sound system. Intracellular electrodes (70-100 M $\Omega, 3 \mathrm{M} \mathrm{KCl}$ filled) were pulled from $1 \mathrm{~mm}$ O.D., $0.7 \mathrm{~mm}$ I.D. quartz glass tubing on a Sutter P-2000 micropipette puller (Sutter Instrument Novato, CA, USA). Signals were amplified and conditioned using laboratory built pre-amplifiers and conditioning amplifiers. Electrodes were advanced using a piezo-activated micropositioner (Marzhause GMBH). The pipette tip was inserted through the RW membrane and into the BM, close to the feet of the OPCs, under visual control. The first cells to be encountered had resting potentials of less than $-80 \mathrm{mV}$, could be held for $10 \mathrm{~s}$ of minutes and were assumed to be supporting cells. Other cells encountered immediately before penetrating the scala media had resting potentials of approximately $-50 \mathrm{mV}$ and could be held for seconds to several minutes. These were presumed OHCs. Loss in sensitivity of the preparation was determined by changes in CM threshold. Losses were never 
encountered as a consequence of intracellular penetration with the electrode. Experiments were terminated immediately there was any loss in CM threshold ( $\geq 5 \mathrm{~dB}$ SPL) due usually to change in the condition of the preparation.

Sound was delivered via a probe with its tip within $1 \mathrm{~mm}$ of the tympanic membrane and coupled to a closed acoustic system comprising two MicroTechGefell GmbH 1-inch MK102 microphones for delivering tones and a Bruel and Kjaer (www.Bksv.co.uk) 3135 0.25-inch microphone for monitoring sound pressure at the tympanum. The sound system was calibrated in situ for frequencies between 1 and $70 \mathrm{kHz}$ by using a laboratory designed and constructed measuring amplifier, and known sound pressure levels (SPLs) were expressed in $\mathrm{dB}$ SPL with reference to $2 \times 10^{-5} \mathrm{~Pa}$. Tone pulses with rise/fall times of $1 \mathrm{~ms}$ were synthesized by a Data Translation 3010 (Data Translation, Marlboro, MA) data acquisition board, attenuated, and used for sound-system calibration and the measurement of electrical and acoustical cochlear responses. To measure DPOAEs, primary tones were set to generate $2 \mathrm{f} 1-\mathrm{f} 2$ distortion products at frequencies between 1 and $50 \mathrm{kHz}$. DPOAEs were measured for levels of $\mathrm{f} 1$ ranging from 10 to $80 \mathrm{~dB}$ SPL, with the levels of the $\mathrm{f} 2$ tone set $10 \mathrm{~dB}$ SPL below that of the f1 tone. DPOAE threshold curves were constructed from measurements of the level of the $\mathrm{f} 2$ tone that produced a $2 \mathrm{f} 1-\mathrm{f} 2$ DPOAE with a level of $0 \mathrm{~dB}$ SPL where the frequency ratio of $\mathrm{f} 2 \mathrm{f} 1 \mathrm{was} 1.23$. System distortion during DPOAE measurements was $80 \mathrm{~dB}$ below the primary tone levels. Tone-evoked $\mathrm{BM}$ displacements were measured by focusing the beam of a self-mixing, laser-diode interferometer ${ }^{62}$ through the RW membrane to form a $20-\mu \mathrm{m}$ spot on the centre of the basilar membrane in the $50-56 \mathrm{kHz}$ region of the cochlea. The interferometer was calibrated at each measurement location by vibrating the piezo stack on which it was mounted over a known range of displacements. At the beginning of each set of BM measurements it was ensured that the $0.2 \mathrm{~nm}$ threshold used as the criterion for threshold was at least as sensitive as the $0 \mathrm{~dB}$ SPL threshold for the DPOAEs before the cochlea was exposed. $\mathrm{BM}$ measurements were checked continuously for changes in the sensitivity of the measurement (due to changes in alignment or fluid on the RW) and for changes in the condition of the preparation. If the thresholds of latter changed by more than $5-10 \mathrm{~dB}$ SPL, the measurements were terminated. Tone pulses with rise/fall times of $1 \mathrm{~ms}$ were used for the basilar membrane measurements. Stimulus delivery to the sound system and interferometer for calibration and processing of signals from the microphone amplifiers, microelectrode recording amplifiers, and interferometer were controlled by a DT3010/32 (Data Translation, Marlboro, MA) board by a PC running Matlab (The MathWorks, Natick, MA) at a sampling rate of $250 \mathrm{kHz}$. The output signal of the interferometer was processed using a digital phase-locking algorithm, and instantaneous amplitude and phase of the wave were recorded.

All measurements were performed blind. Measurements were made from each animal in a litter and data were analysed at the end of each set of measurements. When all measurements had been made from a particular litter, the tissue was genotyped. Randomization was not appropriate because we had no foreknowledge of the genotype, although we could guess it from the phenotype. Phenotypic differences between the WT, heterozygous and homozygous mice were very strong. Thus only sufficient numbers of measurements were made to obtain statistically significant differences. Experiments were terminated ( $<5 \%$ of all measurements) if the physiological state of the preparation changed during a measurement and data from the measurement was excluded.

Data availability. All relevant data are available from the authors.

\section{References}

1. Taberner, A. M. \& Liberman, M. C. Response properties of single auditory nerve fibers in the mouse. J. Neurophysiol. 93, 557-569 (2005).

2. von Békésy, G. \& Wever, E. G. Experiments in Hearing (McGraw-Hill, 1960).

3. Davis, H. A model for transducer action in the cochlea. Cold Spring Harb. Symp. Quant. Biol. 30, 181-190 (1965).

4. Kimura, R. S. Hairs of the cochlear sensory cells and their attachment to the tectorial membrane. Acta Otolaryngol. 61, 55-72 (1966).

5. Sellick, P. M. \& Russell, I. J. The responses of inner hair cells to basilar membrane velocity during low frequency auditory stimulation in the guinea pig cochlea. Hear. Res. 2, 439-445 (1980).

6. Corey, D. P. \& Hudspeth, A. J. Ionic basis of the receptor potential in a vertebrate hair cell. Nature 281, 675-677 (1979).

7. Allen, J. B. Cochlear micromechanics--a physical model of transduction. J. Acoust. Soc. Am. 68, 1660-1670 (1980).

8. Zwislocki, J. J. Theory of cochlear mechanics. Hear. Res. 2, 171-182 (1980).

9. Davis, H. An active process in cochlear mechanics. Hear. Res. 9, 79-90 (1983).

10. Mahendrasingam, S., Macdonald, J. A. \& Furness, D. N. Relative time course of degeneration of different cochlear structures in the CD/1 mouse model of accelerated aging. J. Assoc. Res. Otolaryngol. 12, 437-453 (2011).

11. Forge, A. et al. Gap junctions in the inner ear: comparison of distribution patterns in different vertebrates and assessement of connexin composition in mammals. J. Comp. Neurol. 467, 207-231 (2003).
12. Wingard, J. C. \& Zhao, H.-B. Cellular and deafness mechanisms underlying connexin mutation-induced hearing loss-a common hereditary deafness. Front. Cell. Neurosci. 9, 202 (2015).

13. Bosen, F. et al. The Clouston syndrome mutation connexin $30 \mathrm{~A} 88 \mathrm{~V}$ leads to hyperproliferation of sebaceous glands and hearing impairments in mice. FEBS Lett. 588, 1795-1801 (2014).

14. Dallos, P. \& Evans, B. N. High-frequency motility of outer hair cells and the cochlear amplifier. Science 267, 2006-2009 (1995).

15. Lukashkin, A. N. \& Russell, I. J. Analysis of the f2-f1 and 2 f1-f2 distortion components generated by the hair cell mechanoelectrical transducer: dependence on the amplitudes of the primaries and feedback gain. J. Acoust. Soc. Am. 106, 2661-2668 (1999).

16. Shera, C. A. Mechanisms of mammalian otoacoustic emission and their implications for the clinical utility of otoacoustic emissions. Ear Hear. 25, 86-97 (2004).

17. Wangemann, P. \& Schacht, J. in The Cochlea (eds Dallos, P., Popper, A. N. \& Fay, R. R.) 130-185 (Springer, 1996).

18. Zheng, J. et al. Prestin is the motor protein of cochlear outer hair cells. Nature 405, 149-155 (2000).

19. Santos-Sacchi, J. \& Dilger, J. P. Whole cell currents and mechanical responses of isolated outer hair cells. Hear. Res. 35, 143-150 (1988).

20. Brownell, W. E., Bader, C. R., Bertrand, D. \& de Ribaupierre, Y. Evoked mechanical responses of isolated cochlear outer hair cells. Science 227, 194-196 (1985).

21. Ashmore, J. F. A fast motile response in guinea-pig outer hair cells: the cellular basis of the cochlear amplifier. J. Physiol. 388, 323-347 (1987).

22. He, D. Z. \& Dallos, P. Somatic stiffness of cochlear outer hair cells is voltagedependent. Proc. Natl Acad. Sci. USA 96, 8223-8228 (1999).

23. Robles, L. \& Ruggero, M. A. Mechanics of the mammalian cochlea. Physiol. Rev. 81, 1305-1352 (2001).

24. Ashmore, J. Cochlear outer hair cell motility. Physiol. Rev. 88, 173-210 (2008).

25. Yu, N., Zhu, M.-L. \& Zhao, H.-B. Prestin is expressed on the whole outer hair cell basolateral surface. Brain Res. 1095, 51-58 (2006).

26. Hudspeth, A. J. Making an effort to listen: mechanical amplification in the ear. Neuron 59, 530-545 (2008).

27. Russell, I. J. \& Cowley, E. M. The influence of transient asphyxia on receptor potentials in inner hair cells of the guinea pig cochlea. Hear. Res. 11, 373-384 (1983).

28. Nuttall, A. L. Dynamic aspects of guinea pig inner hair cell receptor potentials with transient asphyxia. Hear. Res. 16, 1-16 (1984).

29. Ruggero, M. A. \& Rich, N. C. Furosemide alters organ of Corti mechanics: evidence for feedback of outer hair cells upon the basilar membrane. J. Neurosci. Off. J. Soc. Neurosci. 11, 1057-1067 (1991).

30. Fettiplace, R. \& Kim, K. X. The physiology of mechanoelectrical transduction channels in hearing. Physiol. Rev. 94, 951-986 (2014).

31. Russell, I. J. \& Kössl, M. Modulation of hair cell voltage responses to tones by low-frequency biasing of the basilar membrane in the guinea pig cochlea. J. Neurosci. Off. J. Soc. Neurosci. 12, 1587-1601 (1992).

32. Johnson, S. L., Beurg, M., Marcotti, W. \& Fettiplace, R. Prestin-driven cochlear amplification is not limited by the outer hair cell membrane time constant. Neuron 70, 1143-1154 (2011).

33. Patuzzi, R. Ion flow in cochlear hair cells and the regulation of hearing sensitivity. Hear. Res. 280, 3-20 (2011).

34. Russell, I. J. Origin of the receptor potential in inner hair cells of the mammalian cochlea--evidence for Davis' theory. Nature 301, 334-336 (1983).

35. Cheatham, M. A., Naik, K. \& Dallos, P. Using the cochlear microphonic as a tool to evaluate cochlear function in mouse models of hearing. J. Assoc. Res. Otolaryngol. 12, 113-125 (2011).

36. Patuzzi, R. B., Yates, G. K. \& Johnstone, B. M. Outer hair cell receptor current and sensorineural hearing loss. Hear. Res. 42, 47-72 (1989).

37. Russell, I. J. \& Kössl, M. Sensory transduction and frequency selectivity in the basal turn of the guinea-pig cochlea. Philos. Trans. R. Soc. Lond. B Biol. Sci. 336, 317-324 (1992).

38. Russell, I. \& Sellick, P. Low-frequency characteristics of intracellularly recorded receptor potentials in guinea-pig cochlear hair cells. J. Physiol. 338, 179-206 (1983).

39. Lukashkin, A. N. et al. A mouse model for human deafness DFNB22 reveals that hearing impairment is due to a loss of inner hair cell stimulation. Proc. Natl Acad. Sci. USA 109, 19351-19356 (2012).

40. Russell, I. J. et al. Sharpened cochlear tuning in a mouse with a genetically modified tectorial membrane. Nat. Neurosci. 10, 215-223 (2007).

41. Allen, J. in Physiology of the Ear 2nd edn (eds Jahn, A. F. \& Santos-Sacchi, J.) 393-442 (Singular Thompson, 2001).

42. Legan, P. K. et al. A targeted deletion in $\alpha$-tectorin reveals that the tectorial membrane is required for the gain and timing of cochlear feedback. Neuron 28, 273-285 (2000). 
43. Legan, P. K. et al. A deafness mutation isolates a second role for the tectorial membrane in hearing. Nat. Neurosci. 8, 1035-1042 (2005).

44. Mellado Lagarde, M. M., Drexl, M., Lukashkina, V. A., Lukashkin, A. N. \& Russell, I. J. Outer hair cell somatic, not hair bundle, motility is the basis of the cochlear amplifier. Nat. Neurosci. 11, 746-748 (2008).

45. Weddell, T. D. et al. Prestin links extrinsic tuning to neural excitation in the mammalian cochlea. Curr. Biol. 21, R682-R683 (2011).

46. Essenfelder, G. M. et al. Connexin 30 mutations responsible for hidrotic ectodermal dysplasia cause abnormal hemichannel activity. Hum. Mol. Genet. 13, 1703-1714 (2004).

47. Teubner, B. et al. Connexin30 (Gjb6)-deficiency causes severe hearing impairment and lack of endocochlear potential. Hum. Mol. Genet. 12, 13-21 (2003).

48. Cohen-Salmon, M. et al. Connexin30 deficiency causes instrastrial fluid-blood barrier disruption within the cochlear stria vascularis. Proc. Natl Acad. Sci. USA 104, 6229-6234 (2007).

49. Boulay, A.-C. et al. Hearing is normal without connexin30. J. Neurosci. Off. J. Soc. Neurosci. 33, 430-434 (2013).

50. Ahmad, S. et al. Restoration of connexin 26 protein level in the cochlea completely rescues hearing in a mouse model of human connexin30-linked deafness. Proc. Natl Acad. Sci. USA 104, 1337-1341 (2007).

51. Ramamoorthy, S., Wilson, T. M., Wu, T. \& Nuttall, A. L. Non-uniform distribution of outer hair cell transmembrane potential induced by extracellular electric field. Biophys. J. 105, 2666-2675 (2013).

52. Fridberger, A. et al. Organ of Corti potentials and the motion of the basilar membrane. J. Neurosci. 24, 10057-10063 (2004).

53. Zidanic, M. \& Brownell, W. E. Fine structure of the intracochlear potential field. I. The silent current. Biophys. J. 57, 1253-1268 (1990).

54. Yu, N. et al. Prestin up-regulation in chronic salicylate (aspirin) administration: an implication of functional dependence of prestin expression. Cell. Mol. Life Sci. 65, 2407-2418 (2008).

55. Sellon, J. B., Ghaffari, R., Farrahi, S., Richardson, G. P. \& Freeman, D. M. Porosity controls spread of excitation in tectorial membrane traveling waves. Biophys. J. 106, 1406-1413 (2014).

56. Ghaffari, R., Aranyosi, A. J., Richardson, G. P. \& Freeman, D. M. Tectorial membrane travelling waves underlie abnormal hearing in Tectb mutant mice. Nat. Commun. 1, 96 (2010).

57. Jones, G. P., Lukashkina, V. A., Russell, I. J., Elliott, S. J. \& Lukashkin, A. N Frequency-dependent properties of the tectorial membrane facilitate energy transmission and amplification in the cochlea. Biophys. J. 104, 1357-1366 (2013).

58. Santos-Sacchi, J. The effects of cytoplasmic acidification upon electrical coupling in the organ of Corti. Hear. Res. 19, 207-215 (1985).

59. Zhao, H. B. \& Santos-Sacchi, J. Effect of membrane tension on gap junctiona conductance of supporting cells in Corti's organ. J. Gen. Physiol. 112, 447-455 (1998).
60. Yu, N. \& Zhao, H.-B. Modulation of outer hair cell electromotility by cochlear supporting cells and gap junctions. PLoS ONE 4, e7923 (2009).

61. Zhu, Y. et al. Active cochlear amplification is dependent on supporting cell gap junctions. Nat. Commun. 4, 1786 (2013).

62. Lukashkin, A. N., Bashtanov, M. E. \& Russell, I. J. A self-mixing laser-diode interferometer for measuring basilar membrane vibrations without opening the cochlea. J. Neurosci. Methods 148, 122-129 (2005).

\section{Acknowledgements}

We thank George Burwood and Patricio Simoes for useful discussion, James Hartley for designing and constructing electronic equipment, and James Bovington for performing the genotyping. We are grateful to Professor Willecke for supplying CD-1Cx30 $488 \mathrm{~V} / \mathrm{A} 88 \mathrm{~V}$ mice. The research was funded by a grant from the Medical Research Council and the German Research Foundation (DFG) through the priority programme 1608

\section{Author contributions}

N.S., A.N.L. and I.J.R. conceived and designed the project. V.A.L. and I.J.R. performed experiments and analysed the data. S.L. performed immunolabelling analysis. I.J.R., A.N.L., N.S. and S.L. contributed to writing the manuscript.

\section{Additional information}

Competing financial interests: The authors declare no competing financial interests.

Reprints and permission information is available online at http://npg.nature.com/ reprintsandpermissions/

How to cite this article: Lukashkina, V. A. et al. A connexin30 mutation rescues hearing and reveals roles for gap junctions in cochlear amplification and micromechanics. Nat. Commun. 8, 14530 doi: 10.1038/ncomms14530 (2017).

Publisher's note: Springer Nature remains neutral with regard to jurisdictional claims in published maps and institutional affiliations.

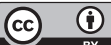

This work is licensed under a Creative Commons Attribution 4.0 International License. The images or other third party material in this article are included in the article's Creative Commons license, unless indicated otherwise in the credit line; if the material is not included under the Creative Commons license, users will need to obtain permission from the license holder to reproduce the material. To view a copy of this license, visit http://creativecommons.org/licenses/by/4.0/

(C) The Author(s) 2017 


\section{Corrigendum: A connexin30 mutation rescues hearing and reveals roles for gap junctions in cochlear amplification and micromechanics}

Victoria A. Lukashkina, Snezana Levic, Andrei N. Lukashkin, Nicola Strenzke \& lan J. Russell

Nature Communications 8:14530 doi: 10.1038/ncomms14530 (2017); Published 21 Feb 2017; Updated 21 Mar 2017

The financial support for this Article was not fully acknowledged. The Acknowledgements should have included the following:

The research was funded by a grant from the Medical Research Council (MR/N004299/1) and the German Research Foundation (DFG) through the priority programme 1608.

This work is licensed under a Creative Commons Attribution 4.0 International License. The images or other third party material in this article are included in the article's Creative Commons license, unless indicated otherwise in the credit line; if the material is not included under the Creative Commons license, users will need to obtain permission from the license holder to reproduce the material. To view a copy of this license, visit http://creativecommons.org/licenses/by/4.0/
}

(C) The Author(s) 2017 